\title{
RESEARCH
}

Open Access

\section{Relationship between weight status and anti-malarial drug efficacy and safety in children in Mali}

Moussa Djimde ${ }^{1,2}$, Hanen Samouda ${ }^{3}$, Julien Jacobs ${ }^{3}$, Hamidou Niangaly' , Mamadou Tekete', Seydou B. Sombie ${ }^{4}$, Erick Josephat Mgina', Bakary Fofana' ' Issaka Sagara', Ogobara K. Doumbo', Michel Vaillant ${ }^{2}$ and Abdoulaye A. Djimde ${ }^{1^{*}}$ (D)

\begin{abstract}
Background: Anti-malarial treatments effectiveness remains a critical challenge for control programmes. However, when drug efficacy is established, the dose is calculated based on a predefined weight according to the patient age. Based on the hypothesis that the standard assumption of weight according to the age when administering the drug could lead to a therapeutic failure potentially due to under-dosing (in the case of overweight) or over-dosing (in case of underweight). In this study, the relationship between weight status and malaria drug efficacy in clearing current Plasmodium falciparum infection and preventing reinfection after treatment was investigated.
\end{abstract}

Methods: Data were drown from a clinical trial conducted previously to investigate malaria drug efficacy in 749 children from Mali (2002-2004). Participants were treated either with artesunate + amodiaquine ( $A S+A Q, n 1=250)$, artesunate + sulfadoxine-pyrimethamine (AS + SP, n2 $=248$ ) or artesunate $(A S, n 3=251)$ and followed for 28 days after treatment. The World Health Organization (WHO) z-score was used to define weight status. A Chi square test was used to compare outcomes according to drugs, weight status and the dynamic of ALAT, ASAT, creatinine and haemoglobin level. Logistic regression models were developed to determine the effect of baseline parameters (weight status, aspartate transaminase, alanine aminotransferase, creatinine and haemoglobin level) on drug efficacy as per WHO criteria.

Results: Without molecular correction, in $\mathrm{AS}+\mathrm{AQ}$ arm, the rate of adequate clinical and parasitological response (ACPR) was higher in the group of underweight children $94.74 \%$ compared to children with normal and overweight (91.24\% and $80.43 \%$ respectively, $P=0.03$ ). After PCR correction, treatment efficacy was similar in the three groups of patients and was above $98 \%(p=0.4)$. Overweight was observed to have no impact on recrudescence. However, it was associated with an increased risk of new infections in the (AS + AQ) $\operatorname{arm}(\mathrm{OR}=0.21,95 \% \mathrm{Cl}[0.06 ; 0.86], p=0.03)$.

Conclusions: The findings suggest that weight deficiency has no deleterious effect on anti-malarial drug efficacy. An increase in the rate of reinfection in overweight children treated by AS + AQ should be further explored in larger studies.

Keywords: Malaria, Weight status, Children, Plasmodium falciparum, Mali

\footnotetext{
*Correspondence: adjimde@icermali.org

${ }^{1}$ Malaria Research and Training Center (MRTC), University of Sciences

of Techniques and Technologies of Bamako (USTTB), Bamako, Mali

Full list of author information is available at the end of the article
} 


\section{Background}

Malaria is a global major public health burden with 212 million cases and 429,000 related deaths estimated in the most recent disease census $[1,2]$. Based on 2015 figures, sub-Saharan Africa remains particularly affected for about $90 \%$ of the worldwide cases and deaths [3].

In Mali, malaria is the leading cause of morbidity and mortality, in particular amongst the youngest $[4,5]$. In 2012, the Demographic and Health Survey reported a prevalence of $52 \%$ deaths due to malaria amongst Malian children under age of five [5], while the World Health Organization (WHO) was estimating about $17 \%$ of related child deaths [6]. One out of five Malian children die even before their 5th year [6]. Amongst the five malaria parasites species infecting humans, Plasmodium falciparum is the most prevalent, causing the highest morbidity and mortality [7].

The interventions currently recommended by the WHO for the management of malaria are the use of longlasting insecticidal mosquito nets, indoor residual spraying for vector control, seasonal malaria chemoprevention (SMC), intermittent preventive treatment for malaria in infants (IPTi), a prompt access to rapid diagnostic testing (RDT) of suspected cases and the treatment of confirmed cases with effective artemisinin-based combination therapy (ACT) [8]. Artesunate + amodiaquine (AS + AQ) is one of the two artemisinin-based combinations recommended by the Malian National Malaria Control Programme and widely used in Mali and known as safe and effective [9, 10]. Artesunate + sulfadoxine-pyrimethamine (AS + SP) is one of the artemisinin-based combinations recommended by the WHO [11], although its use is discouraged. Artesunate (AS) in monotherapy has been administrated as reference treatment of uncomplicated malaria [9]. In the current study, cases enrolled were all uncomplicated falciparum malaria.

Several factors may impact clinical manifestation of malaria, such as the patient's age [12], level of parasitaemia/virulence, particularly P. falciparum [13] and/ or undernutrition [14]. Generally, undernutrition weakens the body system and encourages the development of infections [7], due to micronutrients deficiency and immune system impairment. It has been reported that 450,000 Malians under 5 years have suffered from moderate acute undernutrition in 2013 [15]. In the specific context of malaria infections, this may reduce malaria specific acquired immunity from childhood onwards $[12$, 13].

The effectiveness of anti-malarial treatments remains an ongoing challenge according to the literature [16], particularly in case of reinfection. Usually, the dose of drug to be administered is calculated based on the population weight indices if any. However, a change in weight relative to age when administering the drug could be the cause of a therapeutic failure potentially due to underdosing (in the case of overweight) or over-dosing (in case of underweight).

The use of concomitant medications and/or the patient health conditions might also affect drugs efficacy and safety [17]. Aspartate transaminase (ASAT), alanine aminotransferase (ALAT) and creatinine might be increased, and haemoglobin $(\mathrm{Hb})$ decreased before anti-malarial drug administration and could affect the treatment efficacy and safety.

Here, the efficacy and safety of two artemisinin-based combinations (AS $+\mathrm{AQ}$ and $\mathrm{AS}+\mathrm{SP})$ and artesunate in monotherapy were investigated according to weight status, ASAT, ALAT, creatinine and $\mathrm{Hb}$ level. In addition, $P$. falciparum clearance and prevention of reinfection during post-treatment follow-up in children were addressed.

\section{Methods}

\section{Data handling}

This work is a secondary data analysis from a previous clinical trial (http://www.pactrorg, PACTR201802003020160) conducted to investigate malaria drug efficacy in patients living in BougoulaHameau, Mali, over 3 years (2002-2004). Participants were randomized to receive either $\mathrm{AS}+\mathrm{AQ}, \mathrm{AS}+\mathrm{SP}$, or artesunate monotherapy. In total, 250 participants were treated with "AS (3 days) + AQ (3 days)", 248 with "AS ( 3 days) + SP (1 day)" and 251 with "AS alone (5 days)". The drugs were administered orally at the following dosages: AS ( $4 \mathrm{mg} / \mathrm{kg}$ the $1 \mathrm{st}$ day and $2 \mathrm{mg} / \mathrm{kg}$ other days), AQ $(10 \mathrm{mg} / \mathrm{kg})$ and SP $(25 \mathrm{mg} / \mathrm{kg})$. Patients were followed during 28 days after inclusion. Patients were seen for clinical and biological examinations every day for the first 4 days, then on days 7, 14, 21 and 28 [9].

\section{Weight status}

Weight was measured without shoes but wearing light clothes using a Seca 761 mechanical balance graduated in kilogrammes. For infants unable to stand, the weight was measured with an adult and then the adult weight was subtracted. Height was measured in standing position using a measuring rod graduated in centimetres [18]. WHO free access software AnthroPlus [19] was used to calculate body mass index (BMI) and related z-scores, which were used as proxy of weight status. Weight status definition was based on the following cut-offs points recommended by the WHO in 2007 [20-22]:

- Underweight: BMI z-score <-2 [0-19 years (y) old children].

- Normal weight: $-2 \leq$ BMI z-score $<2$ [ $<5$ years], $-2 \leq$ BMI z-score $<1$ [5-19 years]. 
- Overweight: $2 \leq$ BMI z-score $<3$ [ $<5$ years], $1 \leq$ BMI $\mathrm{z}$-score $<2$ [5-19 years].

- Obesity: BMI z-score $\geq 3$ [ $<5$ years], BMI z-score $\geq 2$ [5-19 years].

- Overweight and obesity: children with overweight and children with obesity have been all aggregated in the overweight group for the analyses.

\section{Drug efficacy and safety}

WHO 28 days in vivo protocol was used to define the efficacy of each treatment arms [23]. For molecular correction outcome, $m s p 1, m s p 2$ and the microsatellite $c a 1$ were used to discriminate recrudescent parasites from reinfection [24]. Patients were classified, with and without molecular correction, having early treatment failure, late clinical failure, late parasitological failure or an adequate clinical and parasitological response [23]. Pretreatment weight status and measures of ASAT, ALAT, creatinine and $\mathrm{Hb}$ level were used to predict drug efficacy. ASAT, ALAT, creatinine and $\mathrm{Hb}$ level were also used to monitor drug safety.

\section{Statistical analysis}

Prevalence of participants with underweight, normal weight and overweight was analysed and descriptive statistics were calculated (percentages, median and quartiles). One way ANOVA was used to compare the anti-malarial drugs doses according to weight status. Chi square test $\left(x^{2}\right)$ was carried out to investigate the associations between weight status, clinical and biological features at enrolment as well as treatment outcome. Logistic regression analyses were performed to analyse the effect of baseline weight status (underweight, overweight including obesity) on the efficacy of the treatment. A second logistic regression model investigated the effect of other baseline parameters, such as ALAT, ASAT, creatinine and $\mathrm{Hb}$ level in addition to weight status, on drug efficacy.

A Beeswarm Boxplots were used to determine median and quartiles of clinical and biological parameters according to children weight status in order to investigate the safety of the treatments. The significance, threshold was set at 0.05. The Rఠ software version 3.5.1 (2018-0702 ) was used for statistical analysis.

\section{Results}

Baseline characteristics are described in Table 1. The distribution of treatment arms $(p=0.11)$ and patients gender $(p=0.95)$ were similar amongst weight status groups. Around $40 \%$ of under 5 years age children had an overweight, $50 \%$ had a normal weight, $10 \%$ had an underweight. Amongst older children, $71 \%$ showed a normal weight, $12 \%$ had an underweight and $17 \%$ had an overweight $(\mathrm{p}<0.0001)$ (Table 1). Within the overweight group, 130 children had overweight and 114 had obesity.

Microscopy has shown that at day 7 only one patient in the underweight and one patient in the normal weight group had positive smear. At day 14, 5.1\% of children in underweight group were carrying malaria parasite

Table 1 General characteristics at enrolment as a function of weight status

\begin{tabular}{|c|c|c|c|c|}
\hline & $\begin{array}{l}\text { Underweight } \\
\mathrm{n}(\%)\end{array}$ & $\begin{array}{l}\text { Normal weight } \\
\mathrm{n}(\%)\end{array}$ & $\begin{array}{l}\text { Overweight } \\
\text { n (\%) }\end{array}$ & p-value \\
\hline$A S+A Q \operatorname{arm}(n=250)$ & $19(7.6)$ & $137(54.8)$ & $94(37.6)$ & 0.11 \\
\hline$A S+S P \operatorname{arm}(n=248)$ & $29(11.69)$ & $138(55.65)$ & $81(32.66)$ & \\
\hline AS arm $(n=251)$ & $30(11.95)$ & $152(60.56)$ & $69(27.49)$ & \\
\hline Male $(n=354)$ & $36(10.17)$ & $201(56.78)$ & $117(33.05)$ & 0.95 \\
\hline Female $(n=395)$ & $42(10.63)$ & $226(57.22)$ & $127(32.15)$ & \\
\hline$<5(n=513)$ & $49(9.55)$ & $259(50.49)$ & $205(39.96)$ & $<0.0001$ \\
\hline$\geq 5(n=236)$ & $29(12.29)$ & $168(71.19)$ & $39(16.53)$ & \\
\hline Temperature $\left({ }^{\circ} \mathrm{C}\right)$ median (interquartile range) & $38.50(37.80,39.18)$ & $38.40(37.80,38.90)$ & $38.65(38.00,39.10)$ & \\
\hline P. falciparum $(/ \mu l)$ median (interquartile range) & $17,800(5925,33,060)$ & $14,850(7162,28,160)$ & $17,660(9638,36,380)$ & \\
\hline Haemoglobin (g/dl) median (interquartile range) & $9.85(8.48,11.40)$ & $10.59(9.50,11.80)$ & $9.50(8.48,10.90)$ & \\
\hline ASAT (UI/I) median (interquartile range) & $32.20(23.30,46.70)$ & $36.00(27.70,43.90)$ & $38.20(29.40,48.30)$ & \\
\hline ALAT (UI/I) median (interquartile range) & $15.15(11.08,20.10)$ & $17.00(12.50,23.87)$ & $23.31(12.00,24.00)$ & \\
\hline Creatinine (mg/dl) median (interquartile range) & $0.52(0.46,0.75)$ & $0.55(0.48,0.68)$ & $0.53(0.44,0.66)$ & \\
\hline Artesunate (mean $\pm \mathrm{SD}$ in $\mathrm{mg} / \mathrm{kg}$ ) & $58.22 \pm 32.29$ & $69.40 \pm 29.39$ & $61.57 \pm 22.77$ & \\
\hline Amodiaquine (mean \pm SD in mg/kg) & $165.08 \pm 69.89$ & $185.3 \pm 89.99$ & $155.82 \pm 48.07$ & \\
\hline Sulfadoxine (mean $\pm S D$ in mg/kg) & $354.17 \pm 185.93$ & $444.85 \pm 194.70$ & $387.66 \pm 199.75$ & \\
\hline
\end{tabular}

$\mathrm{N}$ : frequency; $\mathrm{AS}+\mathrm{AQ}$ : artesunate plus amodiaquine; AS + SP: artesunate + sulfadoxine-pyrimethamine; AS: artesunate; Q1: 25th percentile; Q3: 75th percentile 
compared to $1.6 \%$ and $2.5 \%$ in the normal weight and the overweight groups, respectively $(\mathrm{p}=0.16)$. At day 21 , no parasite was observed in the underweight group, in contrast, blood smear was positive in $7.5 \%$ of children with normal weight and $8.4 \%$ of children with overweight $(p=0.03)$. At day 28 there was no significant difference in parasite carriage $(\mathrm{p}=0.95)$ between the three groups.

The mean $\pm S D$ of the first doses amodiaquine administrated was lower in overweight children $155.82 \pm 48.07 \mathrm{mg} / \mathrm{kg}$ compared to underweight and normal weight children with respectively $165.08 \pm 69.89$ and

Table 2 Treatment outcome without PCR correction

\begin{tabular}{ccccc}
\hline & $\begin{array}{l}\text { Underweight } \\
(\mathbf{n = 2 2})\end{array}$ & $\begin{array}{l}\text { Normal weight } \\
\mathbf{( n = 1 3 7 )} \\
\mathbf{n}(\%)\end{array}$ & $\begin{array}{l}\text { Overweight } \\
\mathbf{n}(\mathbf{n}=\mathbf{9 2})\end{array}$ & p-value \\
$\mathbf{n}(\%)$ & \\
\hline AS+AQ & & & & \\
ACPR & $18(94.74)$ & $125(91.24)$ & $74(80.43)$ & 0.03 \\
ETF & $0(0)$ & $0(0)$ & $1(1.09)$ & - \\
LCF & $3(3.9)$ & $4(2.92)$ & $8(8.7)$ & 0.08 \\
LPF & $1(5.26)$ & $8(5.84)$ & $9(9.78)$ & 0.49 \\
AS+SP & & & & \\
ACPR & $28(96.55)$ & $133(91.24)$ & $75(97.4)$ & 0.92 \\
ETF & $0(0)$ & $0(0)$ & $0(0)$ & - \\
LCF & $0(0)$ & $2(1.47)$ & $1(1.3)$ & 0.81 \\
LPF & $1(3.45)$ & $1(0.74)$ & $1(1.3)$ & 0.49 \\
AS & & & & \\
ACPR & $25(83.33)$ & $105(69.54)$ & $43(63.24)$ & 0.14 \\
ETF & $0(0)$ & $0(0)$ & $0(0)$ & - \\
LCF & $3(10)$ & $15(9.93)$ & $11(16.17)$ & 0.39 \\
LPF & $2(6.67)$ & $31(20.53)$ & $14(20.59)$ & 0.19 \\
\hline
\end{tabular}

ACPR: adequate clinical and parasitological response; ETF: early treatment failure; LCF: late clinical failure, LPF: late parasitological failure
$185.3 \pm 89.99 \mathrm{mg} / \mathrm{kg}(\mathrm{p}=0.04)$ (Table 1). The proportion of adequate clinical and parasitological response (ACPR) after treatment without molecular correction between weight categories, in AS + AQ arm, was higher in the group of children with underweight $94.74 \%$ compared to children with normal weight and overweight (91.24 and $80.43 \%$ respectively, $\mathrm{p}=0.03$ ). After PCR correction, treatment efficacy was similar in the three groups of body weight and was above $98 \%(\mathrm{p}=0.44)$. There was no difference in treatment efficacy in AS + SP and AS-alone arms according to weight status (Table 2). The medians parasite density before treatment were 17,800, 14,850 and 17,660 trophozoites/ $\mu$ l for children with underweight, normal weight and overweight, respectively. Baseline parasite density was higher in underweighted children compared to those with normal weight $(\mathrm{p}=0.03)$.

At enrolment the median of ALAT level (Table 1) although within normal ranges was higher in children with overweight $(23.31 \mathrm{IU} / \mathrm{l})$ compared to children with normal weight (17.00 IU/l) and $15.15 \mathrm{IU} / \mathrm{l}$ in children with underweight $(\mathrm{p}=0.04)$. During the follow-up, at day 7 and day 14 the different weight status groups were similar with regards to ALAT level, p values were 0.37 and 0.89 , respectively (Fig. 1 ).

The ASAT levels were within normal ranges on day 7 with an highest median (Fig. 2) observed in children with overweight (37.91 IU/l) versus $30.90 \mathrm{IU} / 1$ in normal weight and $30.35 \mathrm{IU} / \mathrm{l}$ in underweight groups $(\mathrm{p}=0.03)$. At enrolment and day 14 the three groups were similar, $\mathrm{p}=0.11$ and 0.05 , respectively.

The level of creatinine (Fig. 3) was similar in the three groups of children (normal weight, underweight and overweight) at enrolment ( $p=0.07), 7$ days after the first dose of drugs $(\mathrm{p}=0.41)$ and 14 days $(\mathrm{p}=0.99)$.

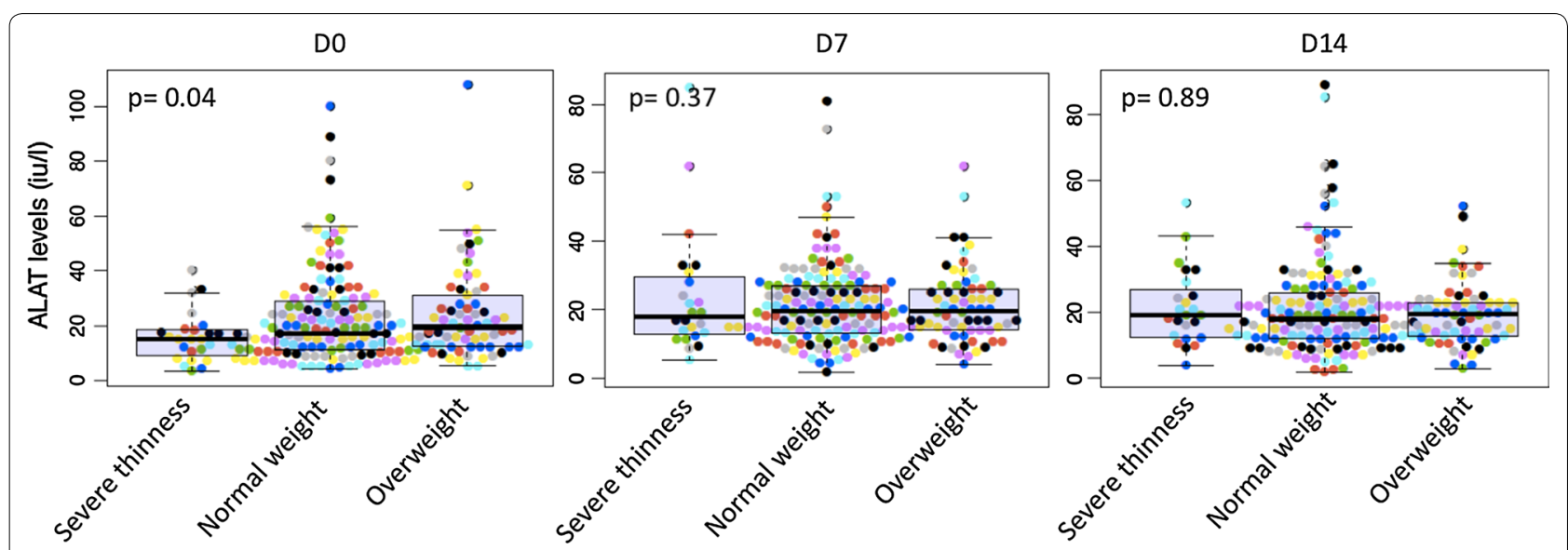

Fig. 1 ALAT level during the follow-up in function of weight status. At day 0 , one patient with normal weight and one other with overweight had respectively 740.25, and $367 \mathrm{U} / \mathrm{I}$ as ASAT level. At day 7, two patients with normal weight had very high ASAT level, respectively 484 and $237 \mathrm{U} / \mathrm{l}$. Outlier values were not included in the figure 


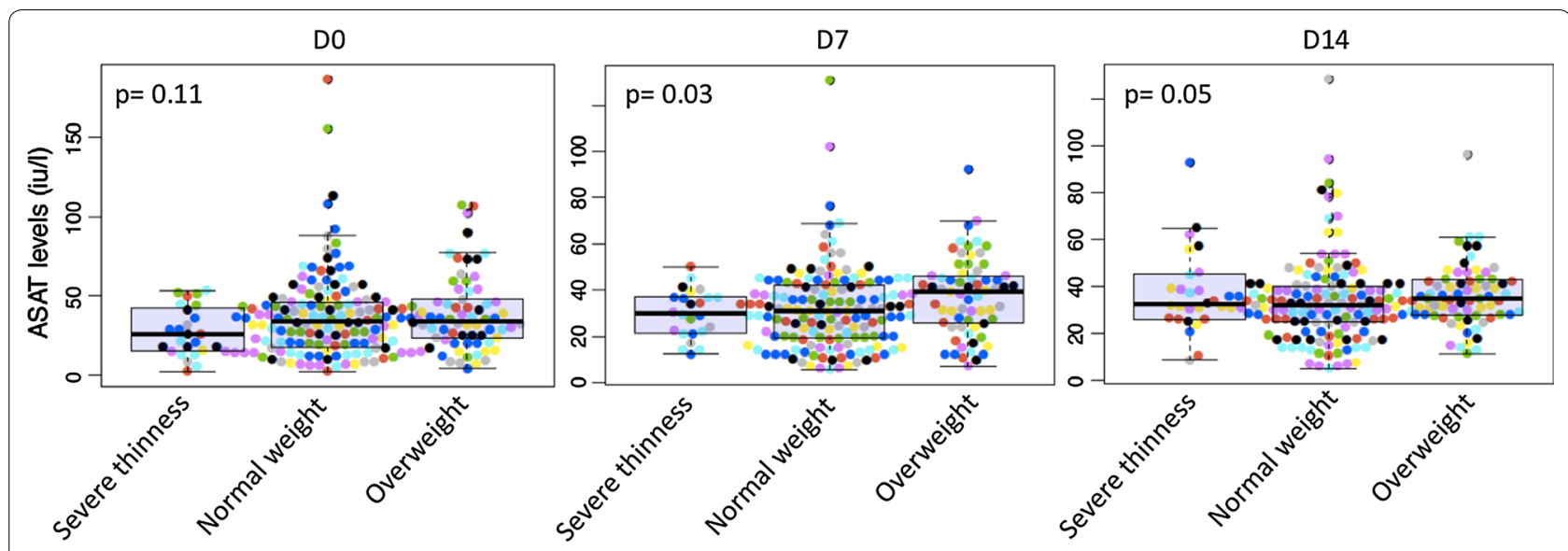

Fig. 2 ASAT level during the follow-up in function of weight status
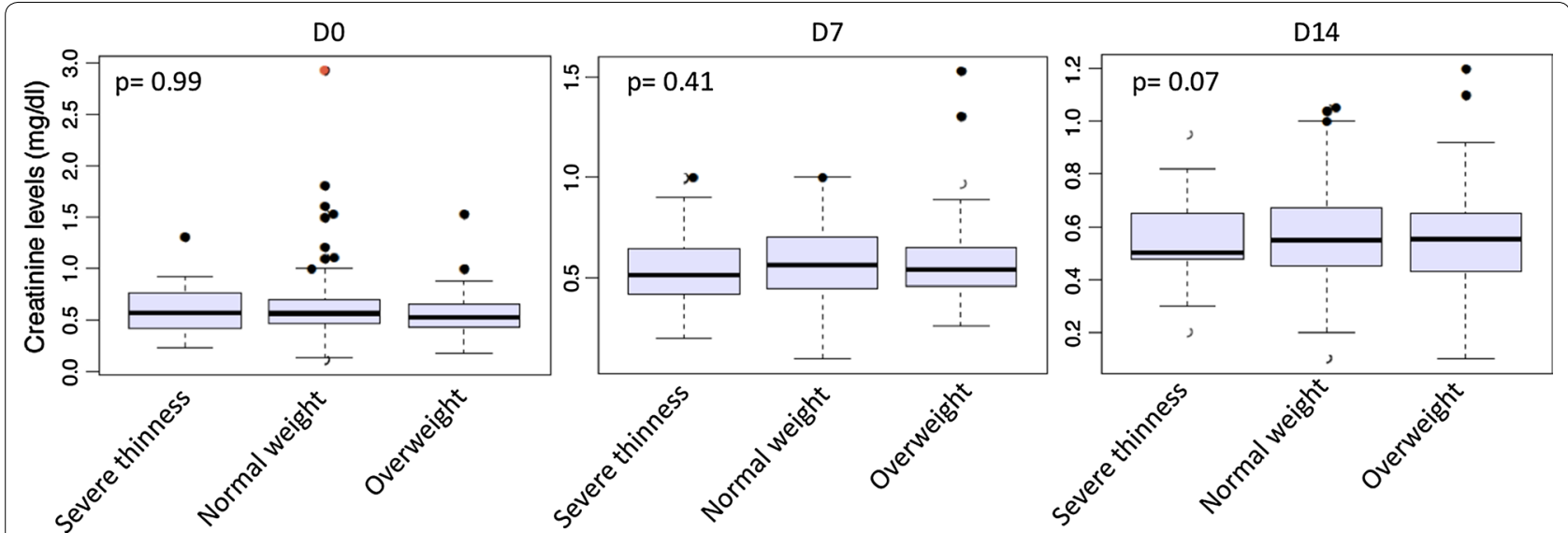

Fig. 3 Creatinine level during the follow-up in function of weight status. At day 0, one patient with normal weight and one patient with overweight had respectively 3.84 and $4.8 \mathrm{mg} / \mathrm{dl}$ as creatinine level. At day 14 one patient with overweight had $6.7 \mathrm{mg} / \mathrm{dl}$ as creatinine level. Outlier values were not included in the figure

The median (Q1, Q3) haemoglobin level at enrolment was lowest in children with overweight $9.50 \mathrm{~g} / \mathrm{dl}(8.48$, 10.90). However, the median of parasite density was similar in children according to weight status (Table 1). Throughout the follow-up, overweight and underweight children appear to have similar haemoglobin level. Children with normal weight had slightly higher haemoglobin level. The p-values were $0.001,0.001$ and 0.01 at enrolment, days 7 and 14, respectively (Fig. 4).

Logistic regression model (Table 3) showed that being overweight was associated with an increased risk of new infections in the "AS+AQ" arm $(\mathrm{OR}=0.21, \mathrm{p}=0.02)$. In the "AS" monotherapy arm, each increase of one unit (IU/l) of ALAT level was observed to be associated with a decrease of the probability of adequate clinical and parasitological response $(\mathrm{OR}=0.95, \mathrm{p}=0.02)$. The used model shows no association between initial weight status, baseline biological parameters and the adequate clinical and biological response after 28 days' follow-up in the "AS + SP" treatment arm.

The multivariate analysis did not show any association between neither the baseline weight status, nor the treatment arm and the evolution of ALAT during the study (Table 4). The multivariate model (Table 4) shows higher ASAT level in children randomized into the "AS + SP" arm before treatment $(\mathrm{p}=0.04)$. Putting together weight status and treatment arm, the model showed that weight deficiency is associated with high ASAT level in the "AS + SP" arm $(\mathrm{p}=0.04)$. After drug administration, whatever the drug used in this study, overweight was associated with an increase of ASAT level at day $7(\mathrm{p}=0.02)$ while no association was observed at 14 days. 


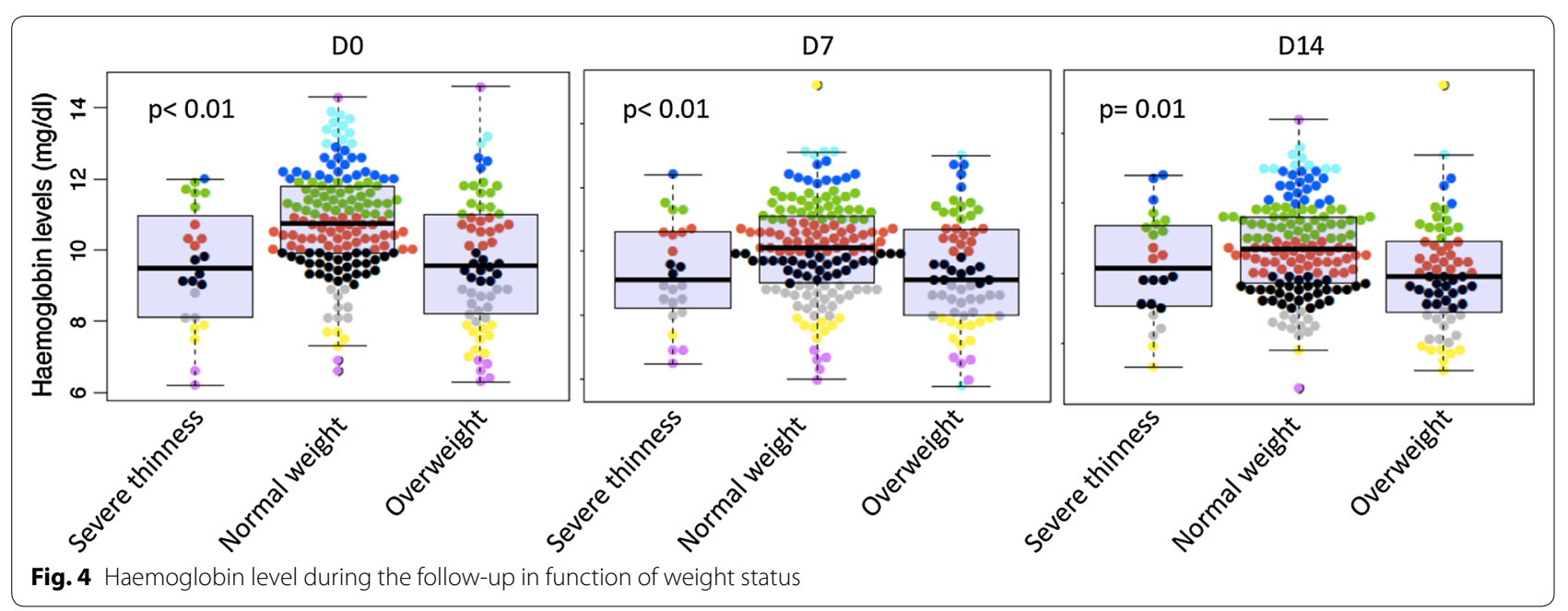

Table 3 Logistic regression model showing the effect of baseline characteristics on the PCR-uncorrected ACPR rate

\begin{tabular}{|c|c|c|c|c|c|}
\hline & Estimate & Std. error & $z$ value & OR $(95 \% \mathrm{Cl})$ & p-value \\
\hline \multicolumn{6}{|c|}{ Artesunate + amodiaquine } \\
\hline Intercept & -0.62 & 2.46 & -0.25 & $0.54(0.004,83.21)$ & 0.80 \\
\hline Underweight & -0.18 & 1.19 & -0.15 & $0.84(0.11,17.69)$ & 0.88 \\
\hline Overweight & -1.54 & 0.66 & -2.34 & $0.21(0.06,0.76)$ & 0.02 \\
\hline Parasitaemia & $1.06 \mathrm{e}-07$ & $1.15 e-05$ & 0.009 & $1(0.99,1)$ & 0.99 \\
\hline ALAT & -0.02 & 0.01 & -1.21 & $0.98(0.95,1.00)$ & 0.22 \\
\hline ASAT & -0.002 & 0.01 & -0.22 & $0.99(0.98,1.02)$ & 0.82 \\
\hline Creatinine & 0.75 & 1.12 & 0.67 & $2.12(0.59,50.83)$ & 0.50 \\
\hline Hb level & 0.27 & 0.21 & 1.29 & $1.31(0.87,2.01)$ & 0.19 \\
\hline \multicolumn{6}{|c|}{ Artesunate + sulfadoxine-pyrimethamine } \\
\hline Intercept & 0.75 & 3.04 & 0.25 & $2.12(0.005,1.00 \mathrm{e}+03)$ & 0.80 \\
\hline Underweight & -0.33 & 1.29 & -0.26 & $0.72(0.07,16.8)$ & 0.79 \\
\hline Overweight & -0.19 & 1.02 & 0.19 & $1.22(0.17,11.2)$ & 0.85 \\
\hline Parasitaemia & $-1.39 e-05$ & $1.65 e-05$ & -0.84 & $0.99(0.99,1)$ & 0.40 \\
\hline ALAT & 0.03 & 0.05 & 0.63 & $1.03(0.94,1.16)$ & 0.53 \\
\hline ASAT & -0.003 & 0.03 & -0.08 & $1(0.95,1.07)$ & 0.53 \\
\hline Creatinine & 5.91 & 3.22 & 1.84 & $369.65(1.39,4.8 \mathrm{e}+05)$ & 0.07 \\
\hline Hb level & -0.16 & 0.29 & -0.56 & $0.99(0.47,1.49)$ & 0.58 \\
\hline \multicolumn{6}{|c|}{ Artesunate in monotherapy } \\
\hline Intercept & -3.56 & 1.97 & -1.80 & $0.03(0.0005,1.18)$ & 0.07 \\
\hline Underweight & 1.14 & 0.94 & 1.21 & $3.11(0.56,25.64)$ & 0.23 \\
\hline Overweight & 0.46 & 0.69 & 0.67 & $1.58(0.42,6.44)$ & 0.50 \\
\hline Parasitaemia & $3.73 e-06$ & $9.42 \mathrm{e}-06$ & 0.39 & $1(0.99,1)$ & 0.69 \\
\hline ALAT & -0.046 & 0.02 & -2.26 & $0.95(0.91,0.99)$ & 0.02 \\
\hline ASAT & 0.003 & 0.008 & 1.03 & $1.01(0.98,1.02)$ & 0.31 \\
\hline Creatinine & 3.39 & 1.83 & 1.85 & $29.77(1.71,2088.11)$ & 0.06 \\
\hline Hb level & 0.24 & 0.17 & 1.49 & $1.27(0.93,1.77)$ & 0.14 \\
\hline
\end{tabular}

ALAT: alanine aminotransferase; ASAT: aspartate aminotransferase; $\mathrm{Hb}$ : haemoglobin

The multivariate model (Table 4) showed an increase in creatinine level is observed at days 7 after the first dose of "AS" uptake $(\mathrm{p}=0.02)$. Putting together weight status and treatment arm, the model showed an association between overweight, "AS" and the increase of creatinine level $(\mathrm{p}=0.03)$. Before treatment and 14 days after drug 


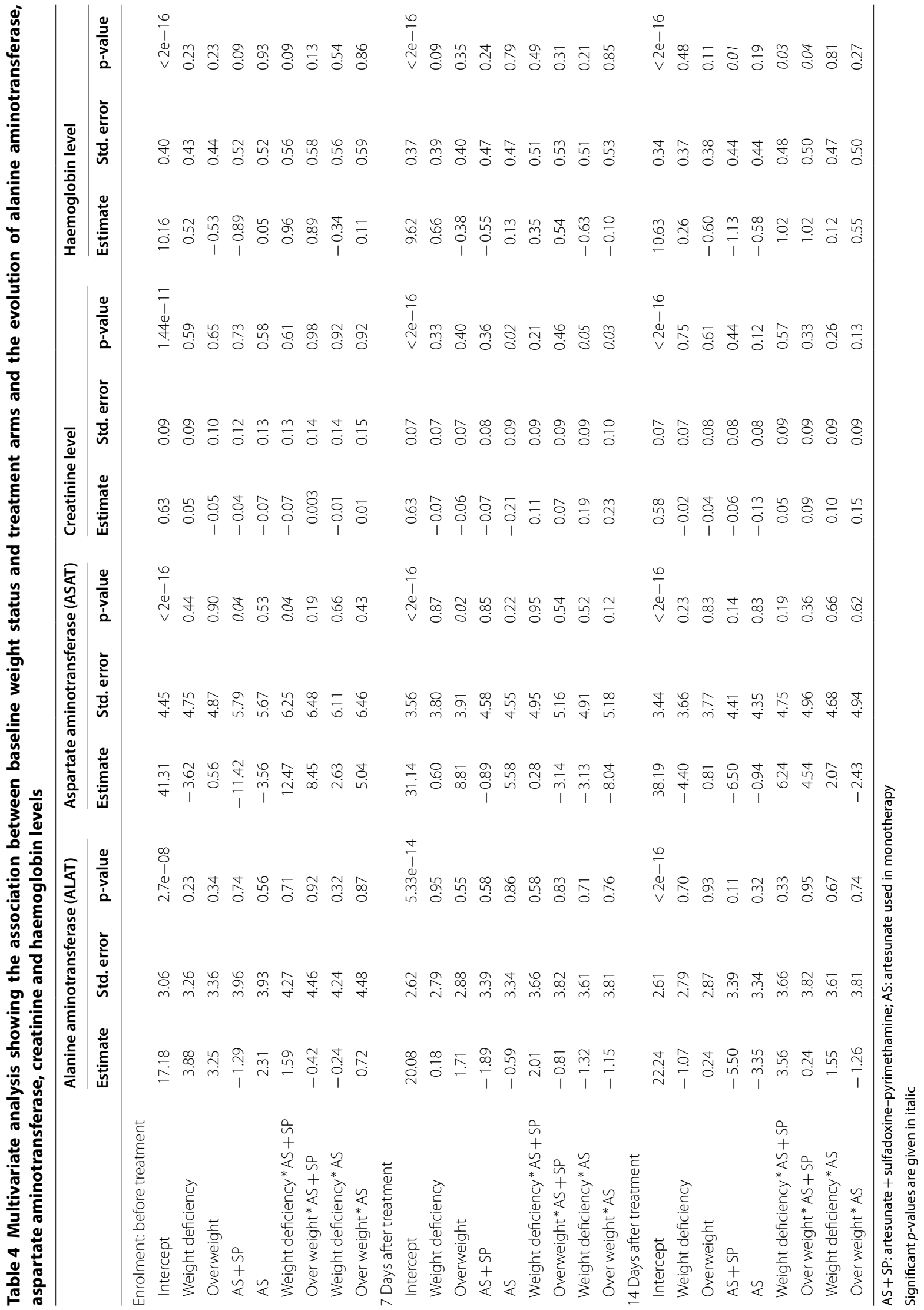


administration no association was observed. The same model showed that at day 14 the decrease of haemoglobin level is associated with the treatment arm "AS + SP" $(p=0.01)$. Putting together weight status and treatment arm in the model, we observe that weight deficiency and "AS + SP" ( $\mathrm{p}=0.03)$; and overweight and "AS + SP" $(\mathrm{p}=0.04)$ are associated with the decrease of haemoglobin level.

\section{Discussion}

The results showed that despite the higher parasite density and lowest haemoglobin level observed in underweight children at enrolment, no association was found between underweight and decreased efficacy or safety of anti-malarial drugs used in this study. Moreover, this analysis showed that overweight tends to increase the risk of new infections in the "AS + AQ" arm. Further investigations are required to scrutinize whether the current treatment regimen of "AS $+\mathrm{AQ}$ " is appropriate for all children.

Out of 749 children enrolled in this study, 244 were in the overweight group and 78 children in the underweight group (Table 1). This trend might be influenced by the severe malnutrition exclusion criterion to the original clinical trial. A study conducted in the same setting in 1995 found a prevalence of chronic malnutrition in children around 25\% [25].

At enrolment, malaria parasite density was higher in underweighted children. The high susceptibility to infection in malnourished children might be explained mainly by the suppression of their immunity because of undernutrition affecting the humoral and cell mediated immunity, the bactericidal activity of phagocytes and complement formation [26]. Although a higher proportion of adequate clinical and parasitological response was observed in children with weight deficiency before PCR correction in the "AS+AQ" arm, all the three groups were similar after PCR correction.

Doses of "AS + AQ" tablets were determined and administered to the children per age categories by assuming their weight according to the age. The decrease of the efficacy of treatment in children with overweight may be related to the underdosing. In contrast, the increase of treatment efficiency in the prevention of new infections in children with underweight could be explained by an effect of overdosing. Taylor et al. [27] described in a previous publication that younger and underweight children have great risk of overdosing and vice versa. In patients with overweight and obesity, iron deficiency are frequently found [28]. Studies show that the frequency of malaria was increased in patients with iron supplementation [29, 30].

The significant association observed between overweight and the increase of ASAT and creatinine levels at day 7 can be explained by the possible accumulation of drugs in fat stores. The lowest haemoglobin level (Fig. 4) was observed in children with weight deficiency before treatment. Ehrhardt et al. [14] reported that anaemia ( $\mathrm{Hb}$ level $<11 \mathrm{~g} / \mathrm{dl}$ ) was associated with young age, parasite density and malnutrition. Müller et al. [31] showed that anaemia was significantly associated with malnutrition. The current analysis found that the uptake of "AS + SP" is associated with a decrease of haemoglobin level more likely du to the role of sulfadoxine and pyrimethamine inhibiting the dihydropteroate synthase and dihydrofolate reductase respectively, both involved in haemoglobin biosynthesis. In combination, their synergy is very high [32].

\section{Conclusion}

Weight deficiency has no deleterious effect on the efficacy of anti-malarial drugs. Underweight status did not affect the drugs tolerability. The decrease of the efficacy of treatment in overweight children treated with artesunate + amodiaquine could be related to an under dosing and should be further explored in larger studies.

\begin{abstract}
Abbreviations
ACPR: adequate clinical and parasitological response; ACT: artemisinin-based combination therapy; ALAT: alanine aminotransferase; AQ: amodiaquine; AS: artesunate; ASAT: aspartate transaminase; BMI: body mass index; ca1: carbonic anhydrase 1; CCMS: Centre of Competence for Methodology and Statistics; CNRFP: Centre National de Recherche et de Formation sur le Paludisme; EPHRU: Epidemiology and Public Health Research Unit; g/dl: grammes per decilitre; Hb: haemoglobin; IPTi: intermittent preventive treatment for malaria in infants; IU/L: international unit per litre; $\mathrm{mg} / \mathrm{kg}$ : milligramme per kilogramme; MRTC: Malaria Research and Training Center; msp 1: merozoite surface protein 1; msp2: merozoite surface protein 2; NIMR: National Institute of Medical Research; OR: odds ratio; PCR: polymerase chain reaction; LIH: LuXembourg Institute of Health; USTTB: University of Sciences of Techniques and Technologies of Bamako; RDT: rapid diagnostic test; SD: standard deviation; SMC: seasonal malaria chemoprevention; SP: sulfadoxine-Pyrimethamine; WHO: World Health Organization; $X^{2}$ : Chi square test.
\end{abstract}

\section{Authors' contributions}

OKD, AAD and IS were responsible for the conception and design of the clinical trial on which based this study. MD, HS and MV conceived this analysis. $I S, H N$, JJ and MD participated to the data management. MD did statistical analysis and wrote the first draft of the paper. All authors contributed to critical review. All authors read and approved the final manuscript.

\section{Author details}

${ }^{1}$ Malaria Research and Training Center (MRTC), University of Sciences of Techniques and Technologies of Bamako (USTTB), Bamako, Mali. ${ }^{2}$ Centre of Competence for Methodology and Statistics (CCMS), Luxembourg Institute of Health (LIH), Strassen, Luxembourg. ${ }^{3}$ Population Health Department, Epidemiology and Public Health Research Unit (EPHRU), Luxembourg Institute of Health, Strassen, Luxembourg. ${ }^{4}$ Centre National de Recherche et de Formation sur le Paludisme (CNRFP), Ouagadougou, Burkina Faso. ${ }^{5}$ National Institute of Medical Research (NIMR), Dar es Salaam, Tanzania.

\section{Acknowledgements}

We thank the population of Bougoula-Hameau for their full participation in the study.

We express our special thanks and gratitude to our mentor Professor Ogobara K. Doumbo who passed away during the review process. His contribution 
has been significant in performing this project. We would have liked otherwise, but unfortunately he has not had the chance to read the final version of this article. We are really thankful to him. May his soul rest in peace.

\section{Competing interests}

The authors declare that they have no competing interests.

\section{Availability of data and materials}

Data are under submission to Springer Research Data Support under reference RDS-SPRN-00075.

\section{Consent for publication}

Not applicable.

\section{Ethics approval and consent to participate}

The protocol was approved by the Ethics Committee of the Faculty of Medicine, Pharmacy and Dentistry, University of Bamako, in Mali. We obtained the consent of the parents or legal guardians of the children before their participation in the study.

\section{Funding}

The main clinical trial [Comparative efficacy, safety and tolerability of three treatment regimens for uncomplicated falciparum malaria: artesunate (3 days) + amodiaquine (3 days) versus artesunate (3 days) + sulfadoxinepyrimethamine ( 1 day) versus artesunate ( 5 days)] work was supported by Access to Medicines, Sanofi-Aventis, and by the International Atomic Energy Agency (Grant RAF/6025). A.A.D. (Abdoulaye A. Djimde) was supported by European and Developing Countries Clinical Trial Partnership Senior Fellowship (Grant 2004.2.C.f1) and Howard Hughes Medical Institution International Scholarship (Grant 55005502). M.D. was supported by a grant from the WHO/ TDR-EDCTP fellowship 2016 programme. The funding bodies had no role in the design of the study and collection, analysis, and interpretation of data and in writing the manuscript.

\section{Publisher's Note}

Springer Nature remains neutral with regard to jurisdictional claims in published maps and institutional affiliations.

Received: 27 March 2018 Accepted: 10 February 2019 Published online: 18 February 2019

\section{References}

1. WHO. World malaria report. Geneva: World Health Organization; 2012. http://www.who.int/malaria/publications/world_malaria_report_2012/ en/. Accessed 17 Mar 2017.

2. WHO. 10 facts on malaria. Geneva: World Health Organization. http:// www.who.int/features/factfiles/malaria/en/. Accessed 7 July 2016.

3. WHO. World malaria report. Geneva: World Health Organization; 2015. http://www.who.int/malaria/media/world-malaria-report-2015/en/. Accessed 17 Mar 2017.

4. Ministère de la Santé du Mali. Plan d'accélération des activités de lutte contre le paludisme, Ministère de la Santé, République du Mali. 2007.

5. PMI. President's malaria initiative, fighting malaria and saving lives. https ://www.pmi.gov/docs/default-source/default-document-library/count ry-profiles/mali_profile.pdf?sfvrsn=18. Accessed 07 July 2016.

6. IRIN. Beating malaria achievable this year gov't says. 2007. http://www. irinnews.org/report/70594/mali-beating-malaria-achievable-year-govtsays. Accessed 7 July 2016.

7. Caulfield LE, Richard SA, Black RE. Undernutrition as an underlying cause of malaria morbidity and mortality in children less than five years old. Am J Trop Med Hyg. 2004;71:55-63.

8. WHO. Malaria: global fund proposal development. Geneva: World Health Organization. http://www.who.int/malaria/publications/atoz/malaria_gf_ proposal_dev_who_policy_brief_201106.pdf. Accessed 1 July 2016.

9. Djimdé AA, Fofana B, Sagara I, Sidibe B, Toure S, Dembele D, et al. Efficacy, safety, and selection of molecular markers of drug resistance by two ACTs in Mali. Am J Trop Med Hyg. 2008;78:455-61.
10. Sagara I, Dicko A, Djimde A, Guindo O, Kone M, Tolo Y, et al. A randomized trial of artesunate-sulfamethoxypyrazine-pyrimethamine versus artemether-lumefantrine for the treatment of uncomplicated Plasmodium falciparum malaria in Mali. Am J Trop Med Hyg. 2006;75:630-6.

11. WHO. Antimalarial drug combination therapy. Geneva: World Health Organization. http://apps.who.int/iris/bitstream/10665/66952/1/WHO_ CDS_RBM_2001.35.pdf. Accessed 21 Sept 2017.

12. Fillol F, Sarr JB, Boulanger D, Cisse B, Sokhna C, Riveau G, et al. Impact of child malnutrition on the specific anti-Plasmodium falciparum antibody response. Malar J. 2009;8:116.

13. Genton B, Al-Yaman F, Alpers MP, Mokela D. Indicators of fatal outcome in paediatric cerebral malaria: a study of 134 comatose Papua New Guinean children. Int J Epidemiol. 1997;26:670-6.

14. Ehrhardt S, Burchard GD, Mantel C, Cramer JP, Kaiser S, Kubo M, et al. Malaria, anemia, and malnutrition in african children-defining intervention priorities. J Infect Dis. 2006;194:108-14.

15. Dicko A. Mali appel global. Kangaba, UNICEF/Mali 2012. Koulikoro Region (Mali). 2014. https://docs.unocha.org/sites/dms/CAP/CAP_2013_Mali.pdf. Accessed 10 Aug 2014.

16. Kokwaro G. Ongoing challenges in the management of malaria. Malar J. 2009;8:S2.

17. Thaul S. How FDA approves drugs and regulates their safety and effectiveness. 2012. https://fas.org/sgp/crs/misc/R41983.pdf. Accessed 21 Sept 2017.

18. WHO. Measuring change in nutritional status. Geneva: World Health Organization. 1983. http://apps.who.int/iris/bitstream/10665/38768 /1/9241541660.pdf. Accessed 21 July 2017.

19. WHO. Application tools, WHO AnthroPlus software. Geneva: World Health Organization. http://www.who.int/growthref/tools/en/. Accessed 17 Mar 2017.

20. de Onis M, Lobstein T. Defining obesity risk status in the general childhood population: which cut-offs should we use? Int J Pediatr Obes. 2010;5:458-60.

21. WHO. Growth reference 5-19 years. Geneva: World Health Organization. http://www.who.int/growthref/who2007_bmi_for_age/en/. Accessed 13 Aug 2017.

22. WHO. Training course on child growth assessment, WHO child growth standards. Geneva: World Health Organization. http://www.who.int/child growth/training/module_c_interpreting_indicators.pdf. Accessed 13 Aug 2017.

23. WHO. Methods for surveillance of antimalarial drug efficacy. Geneva: World Health Organization; 2009. http://apps.who.int/iris/bitst ream/10665/44048/1/9789241597531_eng.pdf. Accessed 13 Aug 2017.

24. Snounou G, Viriyakosol S, Zhu XP, Jarra W, Pinheiro L, do Rosario VE, et al. High sensitivity of detection of human malaria parasites by the use of nested polymerase chain reaction. Mol Biochem Parasitol. 1993;61:315-20.

25. Bouvier P, Papart JP, Wanner P, Picquet M, Rougemont A. Malnutrition of children in Sikasso (Mali): prevalence and socio-economic determinants. Soz Praventivmed. 1995;40:27-34.

26. Scrimshaw NS, SanGiovanni JP. Synergism of nutrition, infection, and immunity: an overview. Am J Clin Nutr. 1997;66:464S-77S.

27. Taylor WRJ, Terlouw DJ, Olliaro PL, White NJ, Brasseur P, Ter Kuileb FO. Use of weight-for-age-data to optimize tablet strength and dosing regimens for a new fixed-dose artesunate-amodiaquine combination for treating falciparum malaria. Bull World Health Organ. 2006;84:956-64.

28. Aigner E, Feldman A, Datz C. Obesity as an emerging risk factor for iron deficiency. Nutrients. 2014;6:3587-600.

29. Murray MJ, Murray AB, Murray MB, Murray CJ. The adverse effect of iron repletion on the course of certain infections. BMJ. 1978;2:1113-5.

30. Oppenheimer SJ, Gibson FD, Macfarlane SB, Moody JB, Harrison C, Spencer A, et al. Iron supplementation increases prevalence and effects of malaria: report on clinical studies in Papua New Guinea. Trans R Soc Trop Med Hyg. 1986;80:603-12.

31. Müller O, Traoré C, Jahn A, Becher H. Severe anaemia in west African children: malaria or malnutrition? Lancet. 2003;361:86-7.

32. Chulay JD, Atkins WM, Sixsmith DG. Synergistic antimalarial activity of pyrimethamine and sulfadoxine against Plasmodium falciparum in vitro. Am J Trop Med Hyg. 1984;33:325-30. 